\title{
A Universal Tare Load Prediction Algorithm for Strain-Gage Balance Calibration Data Analysis
}

\author{
N. Ulbrich* \\ Jacobs Technology Inc., Moffett Field, California 94035-1000
}

\begin{abstract}
An algorithm is discussed that may be used to estimate tare loads of wind tunnel strain-gage balance calibration data. The algorithm was originally developed by R. Galway of IAR/NRC Canada and has been described in the literature for the iterative analysis technique. Basic ideas of Galway's algorithm, however, are universally applicable and work for both the iterative and the non-iterative analysis technique. A recent modification of Galway's algorithm is presented that improves the convergence behavior of the tare load prediction process if it is used in combination with the non-iterative analysis technique. The modified algorithm allows an analyst to use an alternate method for the calculation of intermediate non-linear tare load estimates whenever Galway's original approach does not lead to a convergence of the tare load iterations. It is also shown in detail how Galway's algorithm may be applied to the non-iterative analysis technique. Hand load data from the calibration of a six-component force balance is used to illustrate the application of the original and modified tare load prediction method. During the analysis of the data both the iterative and the non-iterative analysis technique were applied. Overall, predicted tare loads for combinations of the two tare load prediction methods and the two balance data analysis techniques showed excellent agreement as long as the tare load iterations converged. The modified algorithm, however, appears to have an advantage over the original algorithm when absolute voltage measurements of gage outputs are processed using the non-iterative analysis technique. In these situations only the modified algorithm converged because it uses an exact solution of the intermediate non-linear tare load estimate for the tare load iteration.
\end{abstract}

\section{Nomenclature}

$=$ vector containing intercepts of gage outputs that are fitted as a function of loads = axial force

$=$ parts of data reduction matrix that are used with the alternate load iteration equation $=$ parts of data reduction matrix that are used with the primary load iteration equation

$=$ balance load

$=$ vector of predicted balance loads for load iteration step $\xi$

$=$ load dependent matrix that is used in primary and alternate load iteration equation

$=$ load index

$=$ strain-gage output index

$=$ load of a balance calibration data point

$=$ total number of strain-gage outputs

$=$ load series index

$=$ natural zero of a strain-gage balance

$=$ vector of natural zeros

$=$ total number of balance load components

$=$ forward normal force component of a force balance

$=$ aft normal force component of a force balance

* Aerodynamicist, Jacobs Technology Inc. 


\begin{tabular}{|c|c|}
\hline$R$ & $=$ electrical output of a strain-gage \\
\hline $\mathbf{R}$ & $=$ vector containing strain-gage outputs \\
\hline$R M$ & $=$ rolling moment \\
\hline$S$ & $=$ balance load \\
\hline $\mathbf{S}_{\xi}$ & $=$ load vector used in primary and alternate load iteration equation \\
\hline$S 1$ & $=$ forward side force component of a force balance \\
\hline$S 2$ & $=$ aft side force component of a force balance \\
\hline$T$ & $=$ balance load \\
\hline $\mathbf{T}_{\xi}$ & $=$ load vector used in primary and alternate load iteration equation \\
\hline$Z$ & $=$ gage output of zero load point of load series (raw measurement - or- output difference) \\
\hline $\mathbf{Z}$ & $=$ vector of gage outputs of zero load point of load series \\
\hline$\alpha_{0}, \alpha_{1}, \cdots$ & $=$ regression model coefficients of fitted gage outputs (iterative analysis technique) \\
\hline$\beta_{0}, \beta_{1}, \cdots$ & $=$ regression model coefficients of fitted balance loads (non-iterative analysis technique) \\
\hline$\Gamma$ & $=$ original regression model of strain-gage outputs (iterative analysis technique) \\
\hline$\gamma$ & $=$ simplified regression model of strain-gage outputs (iterative analysis technique) \\
\hline$\Delta \mathbf{L}_{\mu}$ & $=$ vector of predicted tare loads for tare load iteration step $\mu$ \\
\hline$\Delta R$ & $=$ strain-gage output difference that is used for load calculation \\
\hline$\Delta \mathbf{R}$ & $=$ vector of strain-gage output differences that is used for iterative load calculation \\
\hline$\Delta \mathbf{R}_{\mathrm{S}}$ & $=$ vector of strain-gage output differences that is used for iterative load calculation \\
\hline$\Delta \mathbf{R}_{\mathrm{T}}$ & $=$ vector of strain-gage output differences that is used for iterative load calculation \\
\hline$\Lambda$ & $=$ original regression model of loads (non-iterative analysis technique) \\
\hline$\lambda$ & $=$ simplified regression model of loads (non-iterative analysis technique) \\
\hline$\mu$ & $=\underline{\text { tare load iteration step index }}$ \\
\hline$\xi$ & $=\underline{\text { load iteration step index }}$ \\
\hline
\end{tabular}

\section{Introduction}

During the past 6 years a new analysis tool called BALFIT was developed at NASA Ames' Balance Calibration Laboratory that performs a multivariate regression analysis of wind tunnel strain-gage balance calibration data (see Refs. [1], [2], and [3] for more detail). BALFIT allows a user to apply a tare load iteration process to the calibration data in order to correctly include the weight of the balance shell, calibration body, calibration fixtures, and weight pans in the calibration loads before the final regression analysis of the calibration data is performed. These tare corrected calibration loads provide important insight into the calibration load schedule design that cannot otherwise be obtained. In addition, the application of tare load corrections to the original calibration loads puts both loads and strain-gage outputs on an "absolute scale" as they are referenced to a common "weightless" state, i.e., the "natural zero state," of the balance. Therefore, the inclusion of tare loads in the balance calibration loads helps avoid a significant systematic error that would otherwise be present in the regression model of the balance calibration data set.

Different techniques are used in the aerospace testing community to estimate tare loads of balance calibration data. A specific tare load prediction algorithm for the iterative analysis technique is described in the literature that may be used for the processing of balance calibration data. This algorithm was originally developed by R. Galway of IAR/NRC in Ottawa, Canada (see Ref. [4], p. 17 and pp. 25-40). Since 2005 the BALFIT software allows a user to apply Galway's original algorithm whenever (i) the iterative analysis technique is applied to balance calibration data and (ii) tare loads need to be estimated.

In 2010 it was decided to implement the non-iterative analysis technique in BALFIT in order to provide better support for wind tunnel customers who prefer the use of this alternate analysis approach (see Ref. [5] for a detailed discussion of the iterative and the non-iterative analysis technique). Therefore, it became necessary to implement a tare load prediction algorithm in BALFIT that would successfully work with the non-iterative analysis technique.

The author concluded that it would be possible to extend Galway's original tare load prediction algorithm to the non-iterative analysis technique by modifying the calculation process that is used to obtain load estimates for each tare load iteration step. The iterative analysis technique fits gage outputs as a 
function of balance loads and uses a data reduction matrix in combination with a load iteration scheme for the calculation of loads. The non-iterative analysis technique, on the other hand, fits balance loads as a function of gage outputs. Then, balance loads are computed by using the corresponding regression models of the balance load components that are stored in a regression coefficient matrix. Consequently, the load calculation parts of Galway's original algorithm only need to be replaced in order to get his method to work for the non-iterative analysis technique.

It was observed during the implementation of Galway's tare load prediction algorithm for the non-iterative analysis technique that the tare load iteration process would not converge or diverge for certain combinations of gage output types and regression models. The author was able to trace the convergence problems to a load calculation approximation that is used in Galway's original algorithm. The author solved the convergence problems after introducing a modified version of Galway's original algorithm that replaces Galway's load calculation approximation with the corresponding exact solution.

In the next section of the paper Galway's original algorithm (Method A) and the modified algorithm (Method B) are first reviewed for the iterative analysis technique. Then, the implementation of both algorithms for the non-iterative analysis technique is discussed. Finally, data from the calibration of a sixcomponent force balance is used to illustrate the tare load iteration convergence characteristics of the two tare load iteration processes.

\section{Tare Load Iteration Process for the Iterative Analysis Technique}

\section{A. General Remarks}

A detailed verbal description of Galway's original tare load iteration process (Method A) for the iterative analysis technique is given in Ref. [4]. Key elements and ideas of Method A are summarized in a flowchart that is shown in Fig. 1a. In principle, Method A uses (i) the regression solution of the strain-gage balance calibration data (i.e., the data reduction matrix) and (ii) the difference between the strain-gage output of a zero load point of a load series and the natural zero as input during each tare load iteration step in order to compute an intermediate tare load estimate for each load series. The strain-gage output of a zero load point of a load series is the output that is caused by the "tare weights" (balance shell, calibration body, and other calibration hardware pieces). The natural zero, on the other hand, is the output of a strain-gage in an assumed "weightless" condition. This "weightless" condition is used to define the global load datum of the balance.

Method A has an important characteristic that is highlighted in blue color in Fig. 1a. It requires only one load calculation for the computation of an intermediate non-linear tare load estimate because it directly uses the difference between the output of the zero load point and the natural zero as input. Method B, on the other hand, uses two load calculation for the computation of an intermediate non-linear tare load estimate because it uses the output of the zero load point and the natural zero separately as input for the load calculation. In that case the tare load estimate is the difference of the two loads that are computed. Figure 1b shows key elements of Method B. Method B is a modified version of Method A because it only differs in the approach that is used to compute the non-linear tare load estimate during the tare load iteration process (the difference between Method A and Method B is highlighted in blue color in Figs. 1a and 1b).

\section{B. Non-Linear Tare Load Estimate}

A more detailed analysis shows that Method A uses an approximation of the non-linear tare load estimate. Method B, on the other hand, uses an exact solution of the non-linear tare load estimate. A better understanding of these two statements can be obtained after reviewing important elements of the iterative analysis technique. This technique first fits the strain-gage outputs as a function of the balance loads. The regression model of a strain-gage output of the balance may have the following form (see, e.g., Ref. [1], Eq. (1))

$$
R(k)=\underbrace{\alpha_{0}(k)}_{\text {intercept }}+\underbrace{\alpha_{1}(k) \cdot F(1)+\cdots+\alpha_{n}(k) \cdot F(n)}_{\text {linear terms }}+\underbrace{\alpha_{n+1}(k) \cdot F(1)^{2}+\cdots}_{\text {non-linear terms }}
$$

where $1 \leq k \leq l$. The solutions of the regression analysis of the balance calibration data, i.e., the regression coefficients $\alpha_{0}, \alpha_{1}, \cdots$, are transformed to data reduction matrix coefficients in order to construct a load 
iteration equation that may be used predict loads from gage outputs during a wind tunnel test. Two load iteration equation choices exist that may be applied for this purpose. The first load iteration equation choice, i.e., the primary iteration equation, and the first solution of the load iteration may be expressed in matrix form as follows:

Primary Iteration Equation (from Ref. [6], p. 12, Table 4)

$$
\begin{gathered}
\mathbf{F}_{\xi}=\left[\mathbf{C}_{\mathbf{1}}^{-1} \Delta \mathbf{R}\right]-\left[\mathbf{C}_{\mathbf{1}}^{-1} \mathbf{C}_{\mathbf{2}}\right] \cdot \mathbf{H}\left(\mathbf{F}_{\xi-\mathbf{1}}\right) \\
\text { first solution } \Longrightarrow \mathbf{F}_{\mathbf{1}}=\mathbf{C}_{\mathbf{1}}^{-\mathbf{\Delta}} \mathbf{\Delta}
\end{gathered}
$$

The second load iteration equation choice, i.e., the alternate iteration equation, and the corresponding first solution have the following form:

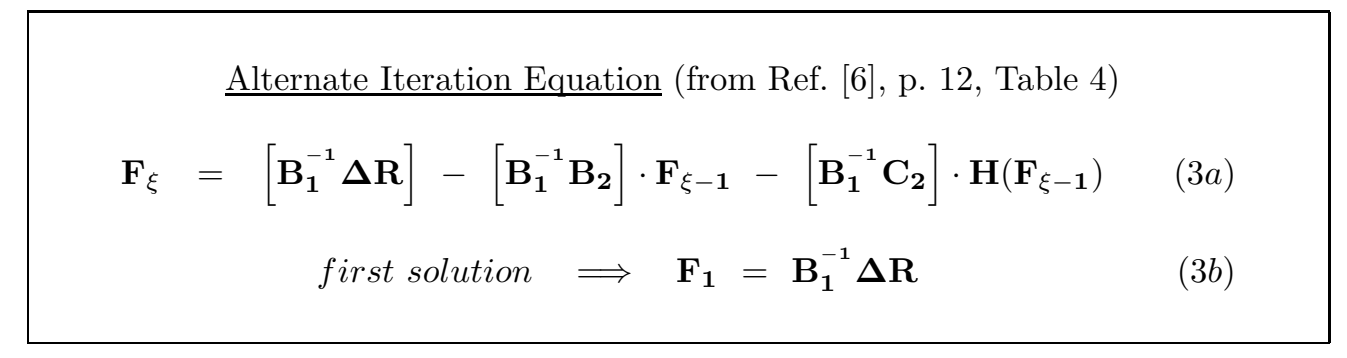

The vector $\mathbf{F}_{\xi}$ represents the load estimates in the iteration equations. The matrices $\mathbf{C}_{\mathbf{1}}, \mathbf{C}_{\mathbf{2}}, \mathbf{B}_{\mathbf{1}}$ and $\mathbf{B}_{\mathbf{2}}$ contain the transformed regression coefficients of the gage outputs. The matrix $\mathbf{H}$ depends on the load estimate from the previous load iteration step. The vector $\Delta \mathbf{R}$ contains the gage outputs that are used as input for the load iteration process. Vector $\Delta \mathbf{R}$ is defined as the difference between the gage output and the intercept of the regression model of the gage outputs (from Ref. [1], Eq. (25)). It can be written as follows:

$$
\text { input for load calculation } \Longrightarrow \mathbf{\Delta}=\mathbf{R}-\mathbf{a}=\underbrace{\left[\begin{array}{c}
R(1) \\
\vdots \\
R(l)
\end{array}\right]}_{\text {gage outputs }}-\underbrace{\left[\begin{array}{c}
\alpha_{0}(1) \\
\vdots \\
\alpha_{0}(l)
\end{array}\right]}_{\text {intercepts }}
$$

The numerical value of the intercept term of the regression model of the gage outputs has two interpretations depending on the gage output type that is used for the analysis. A balance calibration data input file may have been prepared using absolute voltage measurements (gage output type 1). Then, the intercept term is a least squares approximation of the natural zero as the left hand side of Eq. (1) equals the natural zero if all balance loads $F(1), \cdots, F(n)$ are zero. We get:

$$
\text { absolute voltage measurement } \Longrightarrow \alpha_{0}(k) \approx N(k) ; 1 \leq k \leq l
$$

It is also possible to use the difference between the output of a strain-gage and the corresponding natural zero of the gage in a balance calibration data input file (gage output type 2). Then, the intercept terms are a least squares approximation of zero. This can be expressed as follows:

$$
\text { output difference relative to natural zero } \Longrightarrow \alpha_{0}(k) \approx 0 ; 1 \leq k \leq l
$$

The use of gage output differences instead of absolute voltage measurements also means that the intercept term may be omitted in the regression model of the gage outputs.

Now, it is possible to compare Method A and Method B for the iterative analysis technique. Table 1 below summarizes the calculation of the non-linear tare load estimate for each approach. 
Table 1: Calculation of non-linear tare load estimate for Iterative Analysis Technique.

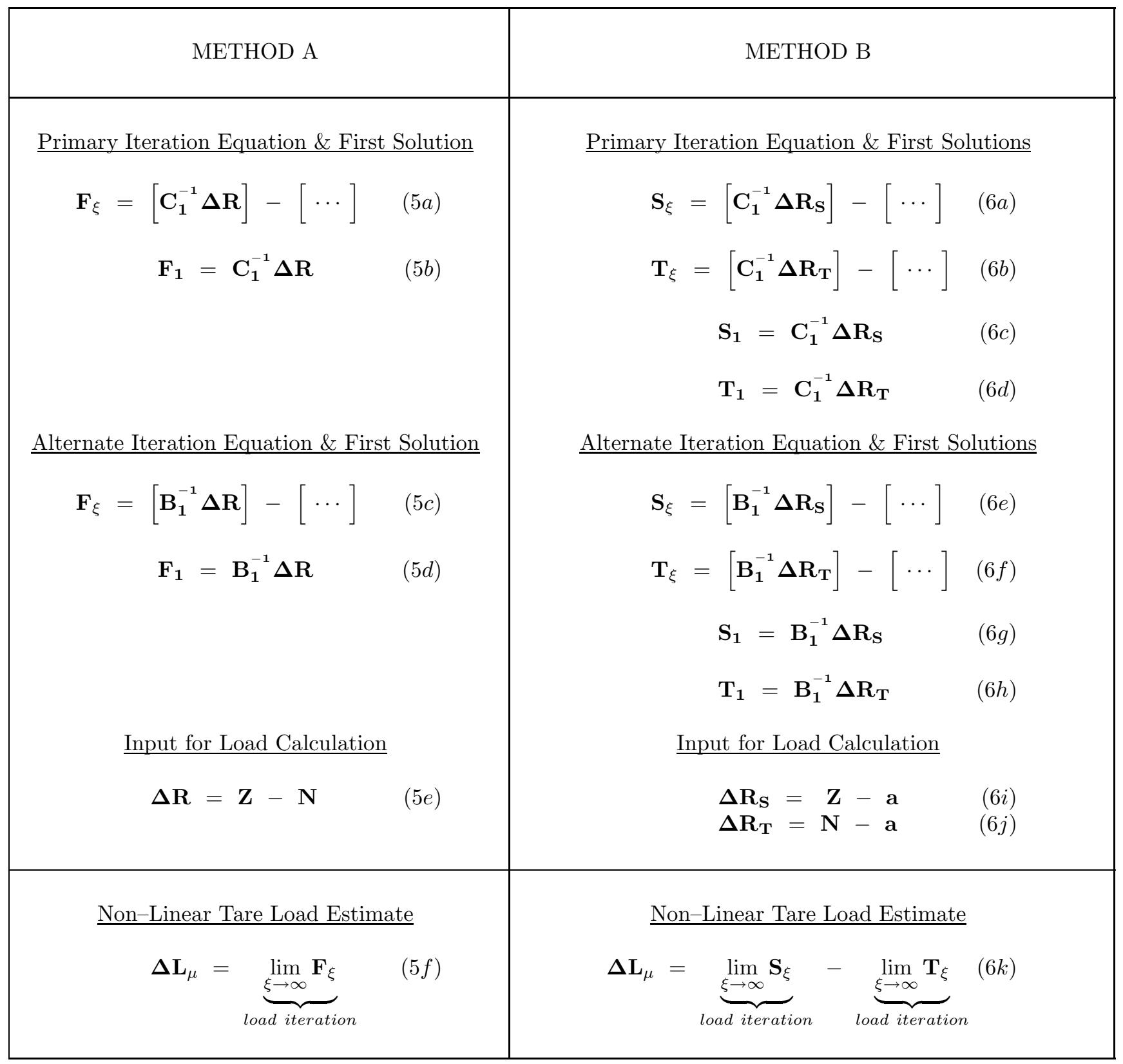

Method A performs one load calculation for the computation of the non-linear tare load estimate (Eq. $(5 f)$ ). Therefore, it uses only one set of gage outputs for the calculation of the non-linear tare load estimate (Eq. (5e)). Method B, on the other hand, uses two load calculations for the same task (Eq. $(6 k)$ ) and needs two sets of gage outputs as input (Eqs. $(6 i),(6 j))$.

\section{Relationship between Method A and Method B}

Comparing Method A with Method B we see that only Method B uses the intercept, i.e., vector a, for the calculation of the non-linear tare load estimate. Method A avoids the use of the intercept even though the intercept is an integral part of the regression model of the gage outputs if it is initially included in the model's term selection. Method A is in some sense an approximation of Method B (i.e., of the exact solution) because Method A appears to use natural zeros to approximate the influence of the intercepts. Method A's 
approximation of the exact solution defined by Method B can be summarized as follows:

$$
\text { Method } A^{\prime} \text { s approximation } \Longrightarrow \mathbf{a} \approx \mathbf{N}
$$

It can rigorously be shown that Method A is an approximation of Method B. The proof starts by using the approximation of Eq. (7a) in Eq. (6i) and comparing the result with Eq. (5e). We get:

$$
\Delta \mathbf{R}_{\mathrm{S}} \approx \Delta \mathrm{R}
$$

In addition, after inserting the approximation defined in Eq. (7a) into Eq. (6j), we get

$$
\Delta \mathbf{R}_{\mathbf{T}} \approx\left[\begin{array}{c}
0 \\
\vdots \\
0
\end{array}\right]
$$

Then, after using the right hand side of Eqs. (7b) in Eq. (6a) (or Eq. (6e)) and comparing the result with Eq. (5a) (or Eq. (5c)), we get

$$
\mathbf{S}_{\xi} \approx \mathbf{F}_{\xi}
$$

Similarly, after using the right hand side of Eq. (7c) in Eq. (6b) (or Eq. $(6 f)$ ), we get

$$
\mathbf{T}_{\xi} \approx\left[\begin{array}{c}
0 \\
\vdots \\
0
\end{array}\right]
$$

Finally, after inserting the relationships given in Eqs. (7d) and (7e) into Eq. (6k) and comparing the result with Eq. $(5 f)$, we get:

$$
\underbrace{\Delta \mathbf{L}_{\mu}}_{\text {Method } A} \approx \underbrace{\Delta \mathbf{L}_{\mu}}_{\text {Method } B}
$$

It is concluded from the above equation that the non-linear tare load estimate of Method A approximates the non-linear tare load estimate of Method B whenever the intercept is replaced by the natural zero.

\section{Exact Agreement between Method A and Method B}

Conditions exist when Method A and Method B are exactly identical. Method A equals Method B whenever (i) a balance calibration data set is given using gage output differences relative to the natural zero and (ii) the intercept term is omitted in the regression model of the gage outputs. Then, the natural zeros used for balance calibration data analysis are "zero" because gage output differences relative to the natural zero are used. We get:

$$
\text { gage output difference relative to natural zero } \Longrightarrow \mathbf{N}=\left[\begin{array}{c}
0 \\
\vdots \\
0
\end{array}\right]
$$

Intercept terms may be omitted in the regression model of gage outputs whenever output differences are used. An omission of intercepts means that the intercepts are exactly zero. Consequently, the intercept term vector becomes the zero vector. We get:

$$
\mathbf{a}=\left[\begin{array}{c}
0 \\
\vdots \\
0
\end{array}\right]
$$

Now, after replacing the natural zero vector used in Eq. (5e) with the vector defined in Eq. (8a), we get:

$$
\Delta \mathbf{R}=\mathbf{Z}
$$


Similarly, after replacing the intercept vector used in Eq. (6i) with the vector defined in Eq. (8b), we get:

$$
\Delta \mathbf{R}_{\mathrm{S}}=\mathbf{Z}
$$

In addition, after replacing the natural zero vector and the intercept vector in Eq. $(6 j)$ with the vectors defined in Eq. (8a) and (8b), we get:

$$
\boldsymbol{\Delta}_{\mathbf{T}}=\left[\begin{array}{c}
0 \\
\vdots \\
0
\end{array}\right]
$$

Then, using Eqs. $(9 a)$ and $(9 b)$ in the load iteration equation choices defined by Eq. $(5 a) \&(5 c)$ and Eq. $(6 a) \&(6 e)$, we get

$$
\mathbf{S}_{\xi}=\mathbf{F}_{\xi}
$$

Similarly, using Eq. (9c) in the load iteration equation choices defined by Eq. (6b) \& $(6 f)$, we get

$$
\mathbf{T}_{\xi}=\left[\begin{array}{c}
0 \\
\vdots \\
0
\end{array}\right]
$$

Finally, after using the relationships $(10 a)$ and $(10 b)$ in Eq. $(6 k)$, i.e., in the formula for the non-linear tare load estimate of Method B, and after comparing the result with Eq. ( $5 f$ ), i.e., the formula for the non-linear tare load estimate for Method A, we get:

$$
\underbrace{\Delta \mathbf{L}_{\mu}}_{\text {Method } A}=\underbrace{\Delta \mathbf{L}_{\mu}}_{\text {Method } B}
$$

The above equation shows that the non-linear tare load estimates for Method A and Method B will be identical if (i) gage output differences relative to the natural zero are used in the balance calibration data input file and (ii) the intercept term is omitted in the regression model of the gage outputs.

\section{Tare Load Iteration Process for the Non-Iterative Analysis Technique}

\section{A. General Remarks}

Strain-gage balance calibration data may also be processed using the non-iterative analysis technique. This approach exchanges the independent and dependent variables that the iterative analysis technique uses. Now, the strain-gage outputs are the independent variables and the balance loads are the dependent variables for the regression analysis of the balance calibration data. Therefore, the balance loads are fitted as a function of the measured strain-gage outputs. The corresponding regression model of the balance loads may have the following form (see Ref. [5], Eq. (2))

$$
F(j)=\underbrace{\beta_{0}(j)}_{\text {intercept }}+\underbrace{\beta_{1}(j) \cdot R(1)+\cdots+\beta_{l}(j) \cdot R(l)}_{\text {linear terms }}+\underbrace{\beta_{l+1}(j) \cdot R(1)^{2}+\cdots}_{\text {non-linear terms }}
$$

where $1 \leq j \leq n$. The non-iterative analysis technique has the advantage that no iteration is needed to compute balance loads from measured strain-gage outputs during a wind tunnel test. The user of the non-iterative analysis technique must only make sure that the final regression model of the loads (Eq. (11)) is always used with compatible strain-gage outputs. In other words, absolute voltage measurements of gage outputs must be used with the regression model defined in Eq. (11) if the regression coefficients were originally computed using absolute voltage measurements. Similarly, gage output differences relative to the natural zero must be used with the regression model defined in Eq. (11) if the regression coefficients were obtained using gage output differences relative to the natural zero. The iterative analysis technique, on the other hand, always uses a gage output difference, i.e., the difference between the gage output and the 
computed intercept term (or another suitable datum), as input for the calculation of balance loads during a wind tunnel test (see also Eq. $(4 a)$ ).

Tare loads caused by the balance shell, calibration body, and other calibration hardware components often need to be estimated before balance calibration data may be analyzed using the non-iterative analysis technique. In 2010 the author concluded that basic elements of Galway's original tare load iteration algorithm (see flowchart in Fig. 1a) may also be used for the non-iterative analysis technique. In addition, the calculation of non-linear tare load estimates may be performed using either Method A (Galway's approach) or Method B (Ulbrich's approach).

\section{B. Non-Linear Tare Load Estimate}

The flowchart in Fig. 2 shows the author's implementation of Galway's tare load iteration algorithm for the non-iterative analysis technique. Either Method A or Method B may be used for the calculation of the non-linear tare load estimate during the tare load iteration process (the two choices are highlighted in blue color in Fig. 2). Table 2 below summarizes the calculation of the non-linear tare load estimates for the non-iterative analysis technique.

Table 2: Calculation of non-linear tare load estimate for Non-Iterative Analysis Technique.

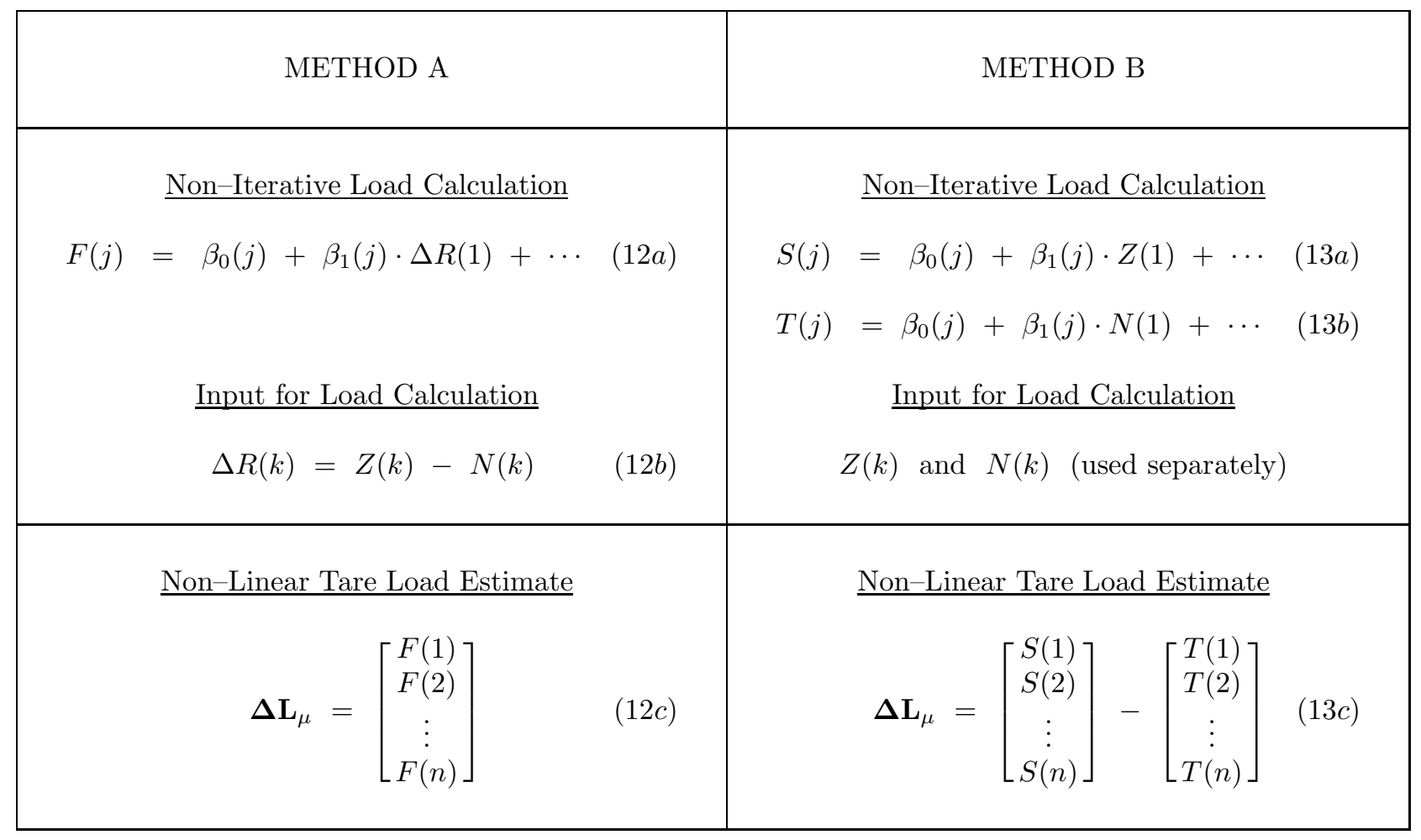

Method A and Method B differ in the number of load calculations that are needed for the computation of the non-linear tare load estimate during the tare load iteration process. Method A needs one load calculation (see Eq. $(12 c)$ ). Method B, on the other hand, requires two load calculations (see Eq. $(\overline{13 c})$ ).

\section{Exact Agreement between Method A and Method B}

The author's experience has shown that the convergence behavior of tare load iteration algorithm for the non-iterative analysis technique depends on the approach that is used to compute the non-linear tare load estimate during the tare load iteration process. Method A appears to be more limited than Method B when it is used in combination with the non-iterative analysis technique. It was observed that Method A only converges for the situation when the non-linear tare load estimates of Method A and of Method B are exactly identical. This situation exists whenever (i) strain-gage balance calibration data is processed using 
gage output differences relative to the natural zero and (ii) the intercept term is omitted in the regression model of the load components. This assertion can be proven mathematically. The proof takes advantage of the fact that the natural zeros used for the tare load iteration process are zero whenever gage output differences relative to the natural zeros are used during the tare load iteration process. Then, we can write:

$$
\text { natural zeros } \Longrightarrow N(1)=N(2)=\cdots=0
$$

In addition, we know from Eq. (11) that the load component $F(j)$ must equal zero whenever the natural zero is used. Therefore, after inserting the modified natural zeros defined in Eq. (14a) into Eq. (11), we conclude that the intercepts must be zero to fulfill the condition. We get:

$$
\text { intercepts of regression models of loads } \Longrightarrow \quad \beta_{0}(j)=0 \text { for } 1 \leq j \leq n
$$

Then, after inserting Eq. (14a) into Eq. (12b), we get the following relationship for the gage outputs that become an input for the load calculation:

$$
\Delta R(k)=Z(k) \text { for } 1 \leq k \leq l
$$

In the next step, after using Eqs. (14b) and (15) in Eq. (12a), we get for the load $F(j)$ of Method A:

$$
F(j)=\beta_{1}(j) \cdot Z(1)+\cdots
$$

Similarly, after using Eq. (14b) in Eq. (13a), we get for the load $S(j)$ of Method B:

$$
S(j)=\beta_{1}(j) \cdot Z(1)+\cdots
$$

Now, after comparing the right hand side of Eq. (16a) with the right hand side of Eq. (16b), we get:

$$
S(j)=F(j) \text { for } 1 \leq j \leq n
$$

We also know, after using Eqs. (14a) and (14b) in Eq. (13b), that the load $T(j)$ of Method B becomes:

$$
T(j)=0 \text { for } 1 \leq j \leq n
$$

Finally, after using Eqs. (17) and (18) in Eq. (13c) and comparing the result with the right hand side of Eq. (12c), we get the relationship:

$$
\underbrace{\Delta \mathbf{L}_{\mu}}_{\text {Method } A}=\underbrace{\Delta \mathbf{L}_{\mu}}_{\text {Method B }}
$$

Equation (19) shows that Method A and Method B are identical for the non-iterative analysis technique only if (i) gage output differences relative to the natural zero are used for the tare load iteration process and (ii) the intercept term is omitted in the regression model of the balance load components.

\section{Discussion of Example}

Data from the calibration of a six-component force balance is used in this section to illustrate the application of the universal tare load prediction algorithm for both the iterative and non-iterative analysis techniques. In addition, the influence of (i) the gage output type (i.e., absolute voltage measurements - or- gage output differences relative to the natural zero) and (ii) the intercept term in the regression models of the dependent variables on the convergence characteristics of the tare load iteration process is investigated.

The Ames MK-III-C strain-gage balance was manufactured by the Task Corporation. It is a sixcomponent force balance that measures five forces and one moment $(N 1, N 2, S 1, S 2, A F, R M)$. It has a diameter of 2.0 inches and a total length of 11.25 inches. Table 3 shows the capacity of each load component of the MK-III-C balance. 
Table 3: Load capacities of MK-III-C balance.

\begin{tabular}{|l|c|c|c|c|c|c|}
\hline & $N 1, \mathrm{lbs}$ & $N 2, \mathrm{lbs}$ & $S 1, \mathrm{lbs}$ & $S 2, \mathrm{lbs}$ & $A F, \mathrm{lbs}$ & $R M, \mathrm{ft}-\mathrm{lbs}$ \\
\hline CAPACITY & 900 & 900 & 450 & 450 & 500 & 100 \\
\hline
\end{tabular}

The balance calibration was performed using the traditional "hand load" method. A total of 247 data points were taken in 13 load series. Combined loadings were only applied to the normal force gages $(N 1$ \& $N 2$ ). The original loads were not tare corrected for the weight of the balance shell, calibration body, and other calibration hardware pieces. Therefore, the calibration data set required the application of a tare load iteration process before the final regression models of the data could be obtained.

The original calibration data of the balance was formated in four different ways so that the iterative and non-iterative analysis techniques could be applied using both absolute voltage measurements (raw measurements) of the gage outputs and gage output differences relative to the natural zeros.

Figure 3a shows the contents of the calibration data input file (i.e., loads, gage outputs, and natural zeros) for the iterative analysis technique if absolute voltage measurements are chosen for the analysis. Figure $3 \mathrm{~b}$ shows the contents of the calibration data input file (i.e., loads, gage outputs, and natural zeros) for the iterative analysis technique if gage output differences relative to the natural zero are chosen for the analysis. All six load components of the balance are needed simultaneously in the input files for iterative analysis technique because the load iteration equation of this analysis technique only works if the number of loads and gage outputs match.

Figure 4a shows the contents of the calibration data input file (i.e., loads, gage outputs, and natural zeros) for the non-iterative analysis technique if absolute voltage measurements are chosen for the analysis. Figure $4 \mathrm{~b}$ shows the contents of the calibration data input file (i.e., loads, gage outputs, and natural zeros) for the non-iterative analysis technique if gage output differences relative to the natural zero are chosen for the analysis. Only the data input files for the $N 1$ load component are shown in Figs. $4 \mathrm{a}$ and $4 \mathrm{~b}$. Input files for the remaining 5 load components were also prepared.

Figure 5a shows results of the tare load iteration convergence study for different combinations of gage output type, regression model, and tare load iteration method that were investigated using the iterative analysis technique. The tare load iteration process converged successfully for all combinations that were studied. It is important to point out that Case 3 and Case 4 were "not allowed" because the direct use of absolute (raw) voltage measurements always requires the presence of an intercept term in the regression model.

Figurew 5b shows the results of the tare load iteration convergence study for different combinations of gage output type, regression model, and tare load iteration method that were investigated using the non-iterative analysis technique. Case 11 and Case 12 were "not allowed" because the direct use of absolute (raw) voltage measurements always requires the presence of an intercept term in the math model. Method B converged successfully for all combinations that were investigated. Method A, on the other hand, only converged when (i) gage output difference relative to the natural zero were used and (ii) no intercept term was included in the regression model of the balance loads (see Case 15 in Fig. 5b).

Figures $6 \mathrm{a}$ and $6 \mathrm{~b}$ show the predicted tare loads of the $N 1$ load component in engineering units for the different cases that were investigated. Figures $7 \mathrm{a}$ and $7 \mathrm{~b}$ show the corresponding predicted tare loads in percent of the load capacity. Overall, the predicted tare loads of the $N 1$ load component show excellent agreement for the 13 load series of the balance calibration data set.

\section{Summary and Conclusions}

Two methods were compared that may be used to estimate tare load corrections whenever wind tunnel strain-gage balance calibration data is analyzed. The methods are universally applicable and work with both the iterative and the non-iterative analysis technique.

The first method, i.e., Method A, was developed by $R$. Galway of IAR/NRC Canada. The second method, i.e., Method B, is a variation of Method A. It was developed in 2010 to address a tare load iteration convergence problem that may occur if Method A is applied in combination with the non-iterative analysis technique. Table 4 summarizes key differences between the two methods. 
Table 4: Summary of key differences between Method A and Method B.

\begin{tabular}{|c|c|c|}
\hline & METHOD A & METHOD B \\
\hline $\begin{array}{l}\text { NUMBER OF LOAD CALCULATIONS NEEDED } \\
\text { FOR NON-LINEAR TARE LOAD ESTIMATE }\end{array}$ & $\begin{array}{l}\text { one load calculation } \\
\text { (approximation of estimate) }\end{array}$ & $\begin{array}{l}\text { two load calculations } \\
\text { (exact solution of estimate) }\end{array}$ \\
\hline $\begin{array}{l}\text { USE OF INTERCEPT TERM WITH } \\
\text { ITERATIVE ANALYSIS TECHNIQUE }\end{array}$ & $\begin{array}{l}\text { intercept replaced } \\
\text { by natural zero }\end{array}$ & $\begin{array}{l}\text { intercept and natural } \\
\text { zero used simultaneously }\end{array}$ \\
\hline
\end{tabular}

Data from the calibration of a six-component force balance was used to investigate the convergence characteristics and accuracy of the two tare load iteration methods. This study showed that (i) the gage output type and (ii) the use of the intercept term in the regression model of the dependent variable influence the convergence characteristics of Method A and Method B. In general, both methods predict the same tare loads as long as the tare load iteration processes converge.

Overall, experience with a wide variety of balance calibration data sets (Task balances, single-piece balance, floor balances) has shown that Method A and Method B will converge for well designed and highly accurate balance calibration data sets if the iterative analysis technique is used. Method B, however, appears to have an advantage over Method A whenever absolute voltage measurements (raw gage outputs) are processed using the non-iterative analysis technique. In these situations it was observed that the tare load iteration process only converges if Method B is applied.

\section{Acknowledgements}

The author would like to thank Tom Volden of Jacobs Technology and Jon Bader of NASA for their critical and constructive review of the final manuscript. The work reported in this paper was supported by the Wind Tunnel Division at NASA Ames Research Center under contract NNA09DB39C.

\section{References}

${ }^{1}$ Ulbrich, N. and Volden, T., "Strain-Gage Balance Calibration Analysis Using Automatically Selected Math Models," AIAA 2005-4084, paper presented at the 41st AIAA/ASME/SAE/ASEE Joint Propulsion Conference and Exhibit, Tucson, Arizona, July 2005.

${ }^{2}$ Ulbrich, N. and Volden, T., "Development of a New Software Tool for Balance Calibration Analysis," AIAA 2006-3434, paper presented at the 25th AIAA Aerodynamic Measurement Technology and Ground Testing Conference, San Francisco, California, June 2006.

${ }^{3}$ Ulbrich, N., "Optimization of Regression Models of Experimental Data using Confirmation Points," AIAA 2010-0930, paper presented at the 48th AIAA Aerospace Sciences Meeting and Exhibit, Orlando, Florida, January 2010.

${ }^{4}$ AIAA/GTTC Internal Balance Technology Working Group, "Recommended Practice, Calibration and Use of Internal Strain-Gage Balances with Application to Wind Tunnel Testing," AIAA R-091-2003, American Institute of Aeronautics and Astronautics, Reston, Virginia, 2003, p. 17, pp. 25-40. Personal communication with the authors of AIAA R-091-2003 confirmed that the tare load prediction algorithm recommended in the document was originally developed by R. Galway of IAR/NRC, Canada.

${ }^{5}$ Ulbrich, N., "Comparison of Iterative and Non-Iterative Strain-Gage Balance Load Calculation Methods," AIAA 2010-4202, paper presented at the 27th AIAA Aerodynamic Measurement Technology and Ground Testing Conference, Chicago, Illinois, June/July 2010.

${ }^{6}$ Ulbrich, N. and Volden, T., "Application of a New Calibration Analysis Process to the MK-III-C Balance," AIAA 2006-0517, paper presented at the 44th AIAA Aerospace Sciences Meeting and Exhibit, Reno, Nevada, January 2006. 


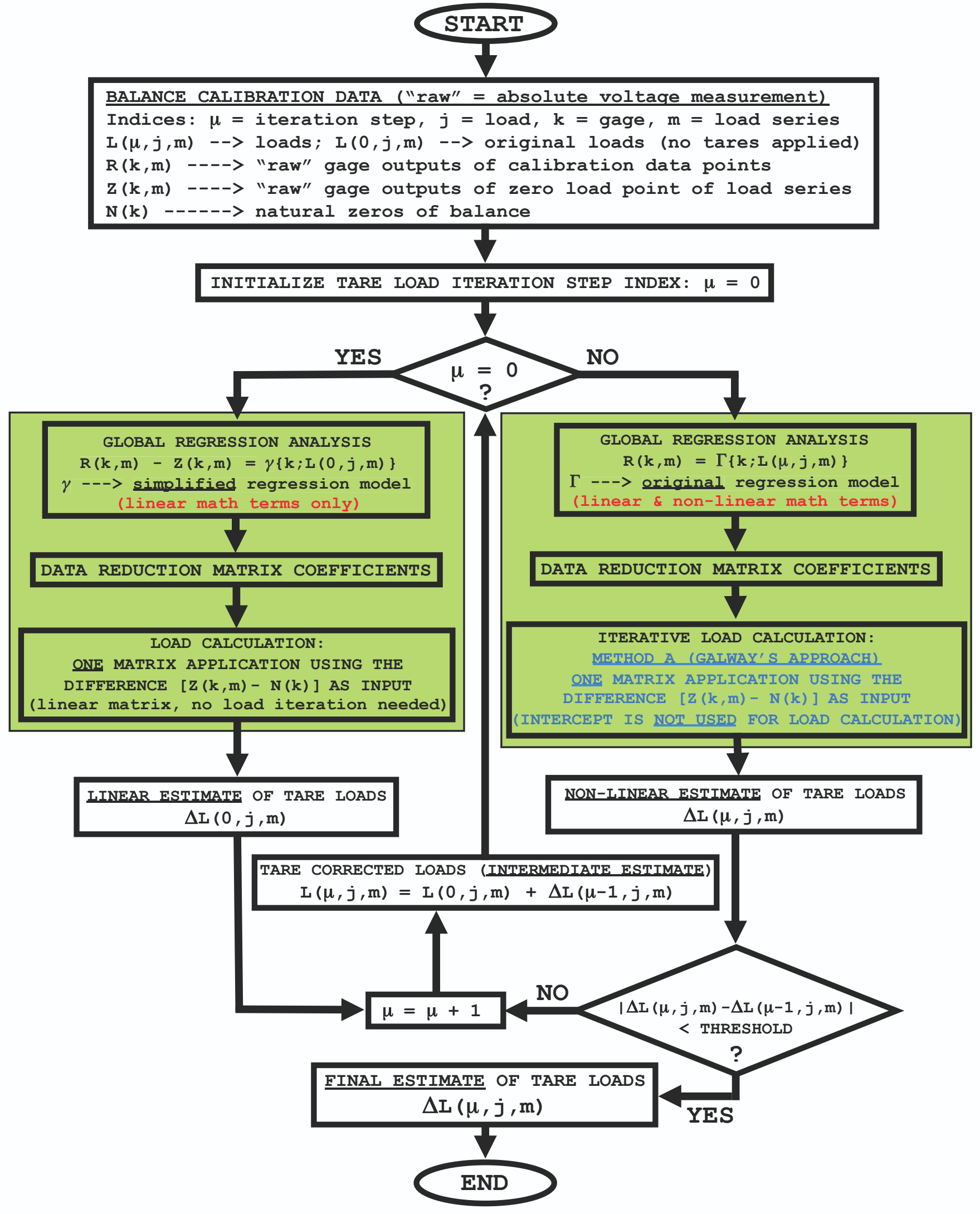

Fig. 1a Method A: Galway's original tare load prediction algorithm for the Iterative Analysis Technique. 


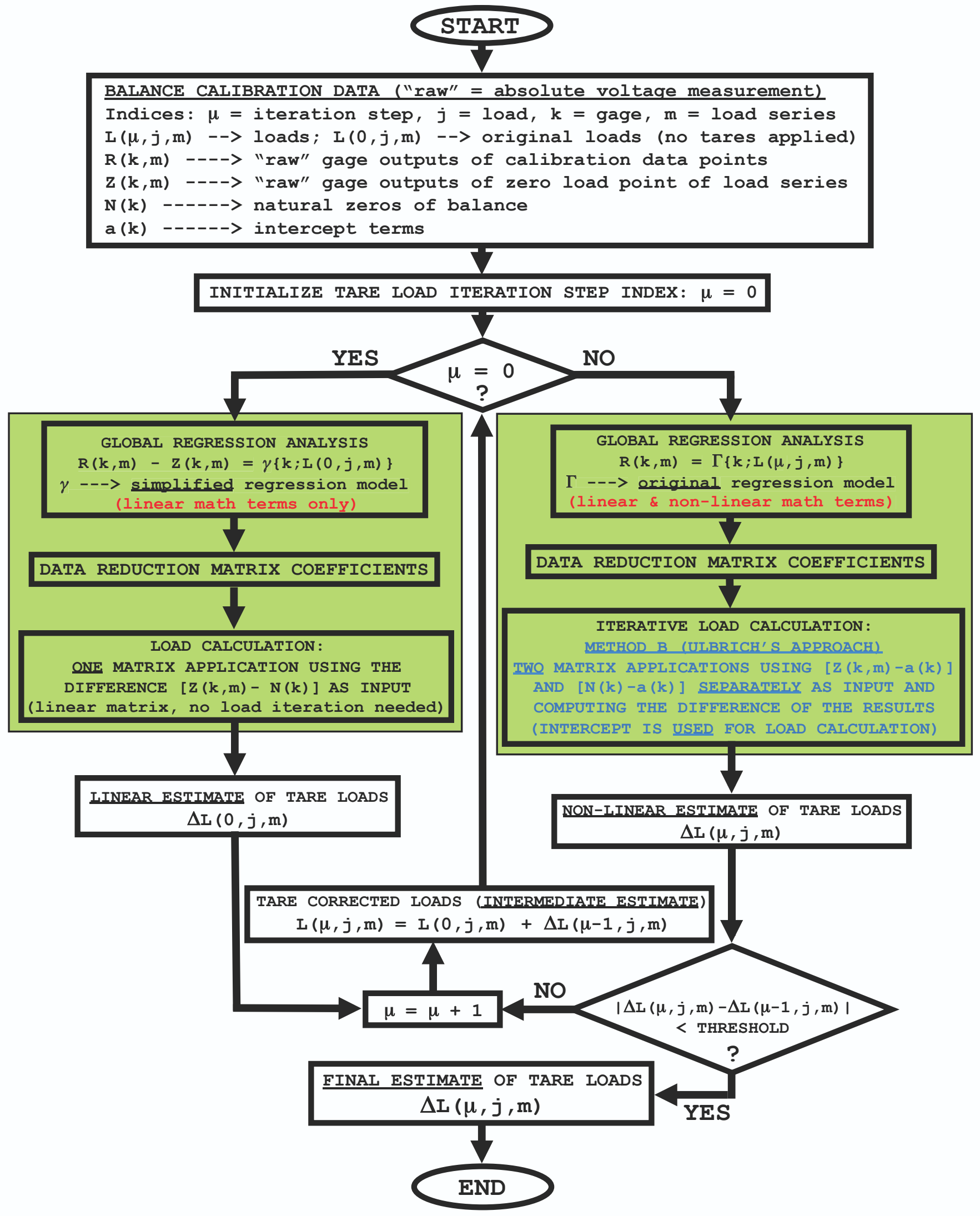

Fig. 1b $\underline{\text { Method B: Ulbrich's variation of Galway's tare load prediction algorithm for the Iterative Analysis Technique. }}$ 


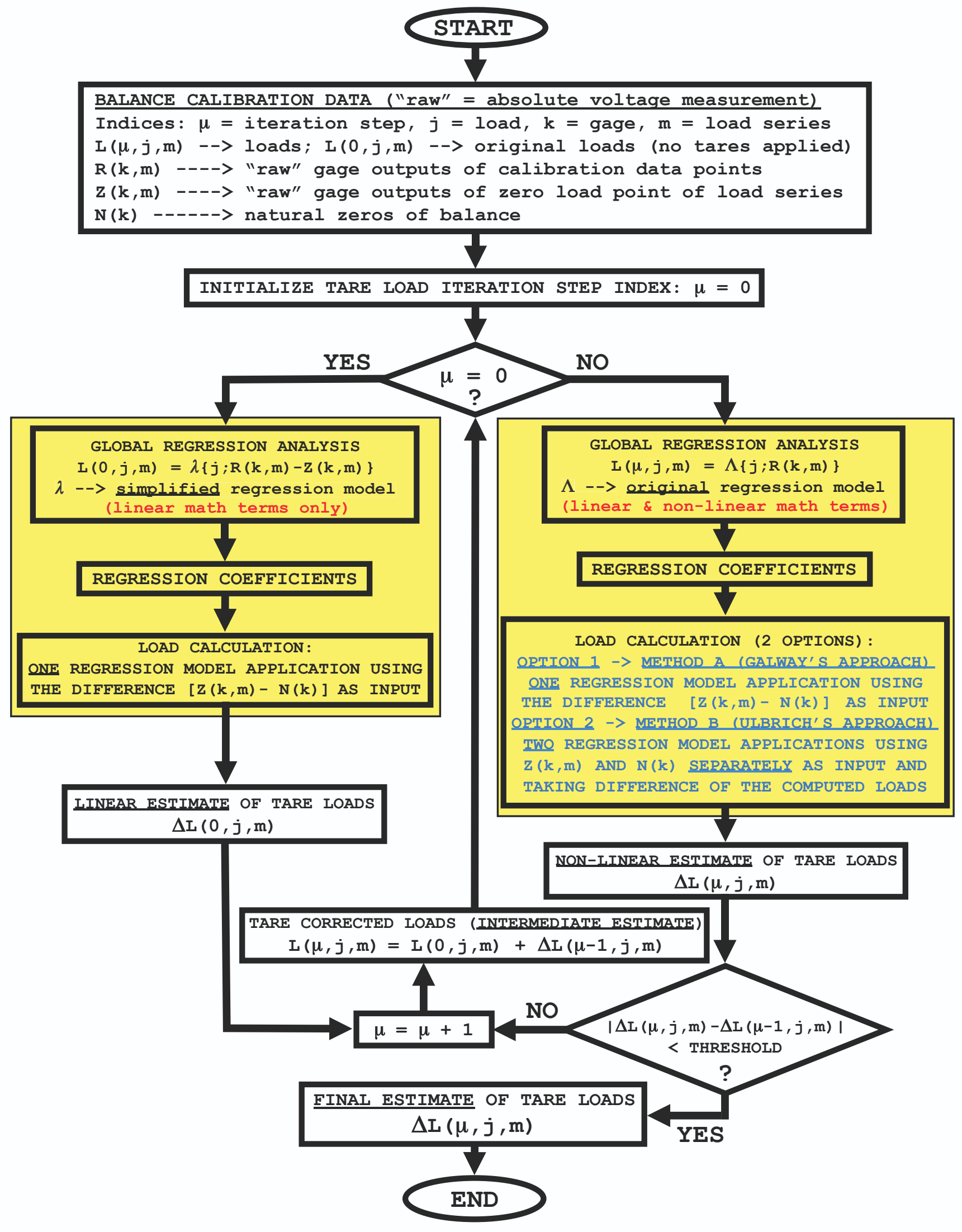

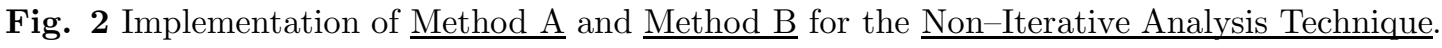




\begin{tabular}{|c|c|c|c|c|c|c|c|c|c|c|c|c|c|}
\hline & & & & & & & & \multicolumn{6}{|c|}{ NATURAL ZEROS (GAGE OUTPUTS AS ABSOLUTE VOLTAGE MEASUREMENTS) } \\
\hline & & & & & & & & $R 1$ & $R 2$ & $R 3$ & R4 & R5 & R6 \\
\hline & & & & & & & & microV $/ V$ & microV $/ V$ & microv/V & microV $/ V$ & microV/V & $\operatorname{microv} / V$ \\
\hline & & & & & & & & -318.58 & 95.28 & 55.89 & -212.30 & 169.44 & -102.23 \\
\hline \multicolumn{14}{|c|}{$\begin{array}{l}\text { BALANCE CALIBRATION DATA (GAGE OUTPUTS AS ABSOLUTE VOLTAGE MEASUREMENTS ; } 21 \text { OF } 247 \text { POINTS SHOWN) } \\
\text { ABBREVIATIONS: (indep.) }=\text { independent variable ; (dep.) = dependent variable }\end{array}$} \\
\hline PT. ID & SERIES & N1 & N2 & S1 & 52 & $A F$ & $R M$ & $R 1$ & $R 2$ & $R 3$ & $R 4$ & $R 5$ & $R 6$ \\
\hline & & (indep.) & (indep.) & (indep.) & (indep.) & (indep.) & (indep.) & (dep.) & (dep.) & (dep.) & (dep.) & (dep.) & (dep.) \\
\hline- & - & Ibs & Ibs & Ibs & Ibs & Ibs & ft-lbs & microv $/ V$ & microv $/ V$ & microv $/ V$ & microv $/ V$ & microv $/ V$ & $\operatorname{microv} / V$ \\
\hline $\mathrm{P}-1$ & I & 0 & 0 & 0 & 0 & 0 & 0 & -239.01 & 108.67 & 55.80 & -211.46 & 170.56 & -102.38 \\
\hline P-2 & I & 100 & 0 & 0 & 0 & 0 & 0 & -59.90 & 105.07 & 56.21 & -210.96 & 170.53 & -102.37 \\
\hline $\mathrm{P}-3$ & I & 200 & 0 & 0 & 0 & 0 & 0 & 120.30 & 101.70 & 56.67 & -210.46 & 170.16 & -102.56 \\
\hline P-4 & I & 300 & 0 & 0 & 0 & 0 & 0 & 301.18 & 98.20 & 56.92 & -210.05 & 169.99 & -102.47 \\
\hline $\mathrm{P}-5$ & I & 400 & 0 & 0 & 0 & 0 & 0 & 482.15 & 94.78 & 56.83 & -209.89 & 169.80 & -102.61 \\
\hline P-6 & I & 500 & 0 & 0 & 0 & 0 & 0 & 663.20 & 91.43 & 57.28 & -209.37 & 169.71 & -102.40 \\
\hline P-7 & I & 600 & 0 & 0 & 0 & 0 & 0 & 843.98 & 87.96 & 57.31 & -209.03 & 169.53 & -102.57 \\
\hline P-8 & I & 700 & 0 & 0 & 0 & 0 & 0 & 1024.69 & 84.46 & 57.18 & -208.81 & 169.53 & -102.53 \\
\hline$P-9$ & I & 800 & 0 & 0 & 0 & 0 & 0 & 1204.81 & 80.95 & 57.27 & -208.49 & 169.25 & -102.57 \\
\hline$P-10$ & I & 900 & 0 & 0 & 0 & 0 & 0 & 1385.42 & 77.52 & 57.42 & -208.20 & 169.28 & -102.40 \\
\hline P-11 & I & 800 & 0 & 0 & 0 & 0 & 0 & 1207.31 & 80.99 & 57.23 & -208.62 & 169.24 & -102.54 \\
\hline P-12 & I & 700 & 0 & 0 & 0 & 0 & 0 & 1028.10 & 84.36 & 57.01 & -208.80 & 169.43 & -102.51 \\
\hline$P-13$ & I & 600 & 0 & 0 & 0 & 0 & 0 & 847.66 & 87.95 & 57.17 & -209.02 & 169.44 & -102.62 \\
\hline P-14 & I & 500 & 0 & 0 & 0 & 0 & 0 & 666.39 & 91.42 & 56.72 & -209.31 & 169.40 & -102.77 \\
\hline P-15 & I & 400 & 0 & 0 & 0 & 0 & 0 & 485.03 & 94.83 & 56.96 & -209.89 & 169.60 & -102.51 \\
\hline P-16 & I & 300 & 0 & 0 & 0 & 0 & 0 & 303.36 & 98.27 & 56.63 & -210.23 & 169.78 & -102.52 \\
\hline$P-17$ & I & 200 & 0 & 0 & 0 & 0 & 0 & 121.73 & 101.71 & 56.55 & -210.57 & 169.89 & -102.43 \\
\hline P-18 & I & 100 & 0 & 0 & 0 & 0 & 0 & -59.20 & 105.21 & 56.39 & -210.90 & 170.34 & -102.41 \\
\hline P-19 & I & 0 & 0 & 0 & 0 & 0 & 0 & -239.60 & 108.69 & 55.78 & -211.44 & 170.66 & -102.35 \\
\hline P-20 & II & 0 & 0 & 0 & 0 & 0 & 0 & -297.66 & 166.53 & 55.96 & -212.57 & 173.44 & -102.40 \\
\hline P-21 & II & 0 & 100 & 0 & 0 & 0 & 0 & -299.37 & 351.63 & 56.07 & -213.30 & 177.60 & -102.55 \\
\hline$\ldots$ & $\ldots$ & $\ldots$ & $\ldots$ & $\ldots$ & $\ldots$ & $\ldots$ & $\ldots$ & ... & $\ldots$ & $\ldots$ & ... & ... & ... \\
\hline
\end{tabular}

Fig. 3a Iterative Analysis Technique: Balance calibration data using absolute voltage measurements.

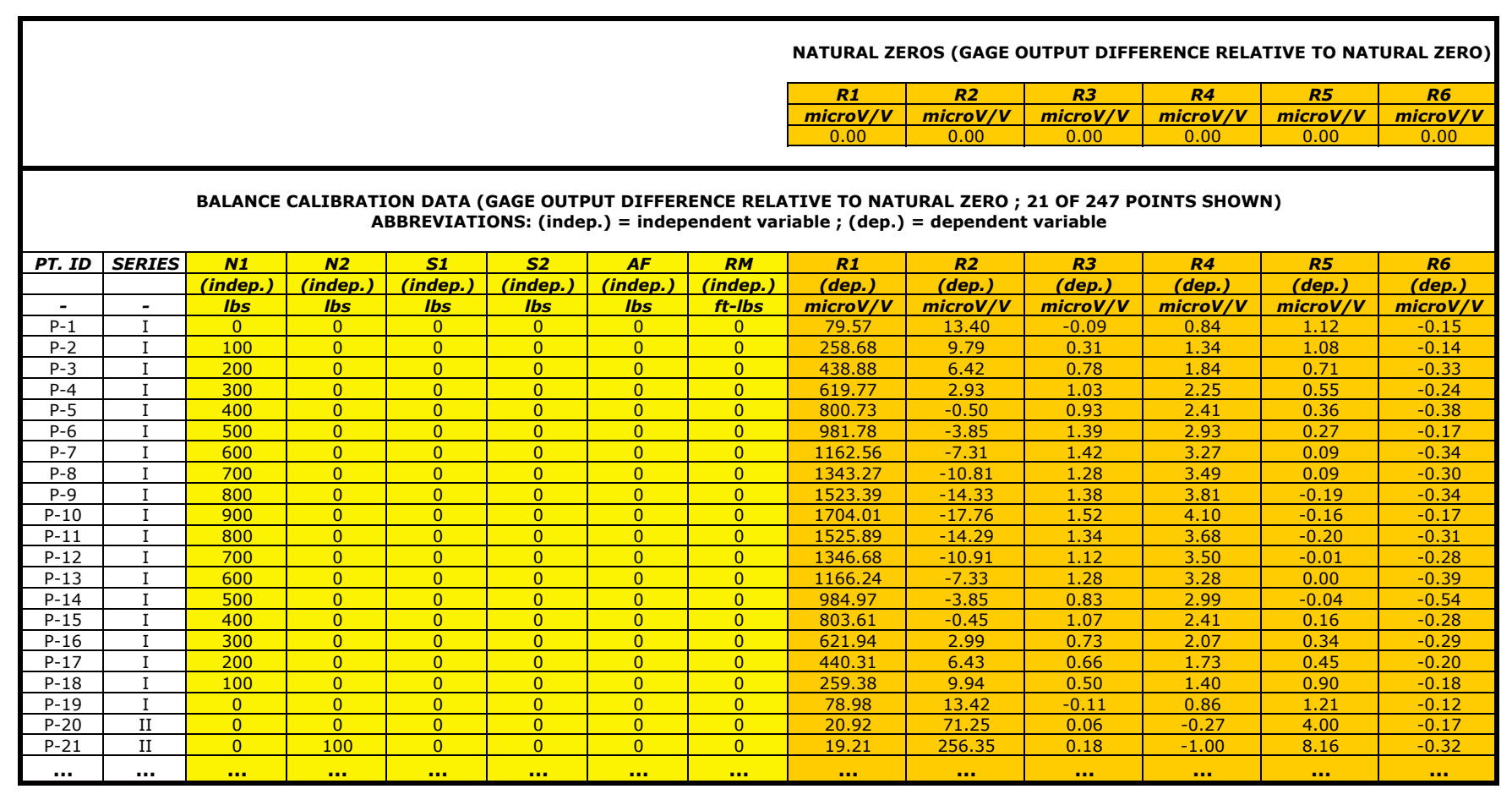

Fig. 3b Iterative Analysis Technique: Balance calibration data using gage output differences.

American Institute of Aeronautics and Astronautics 


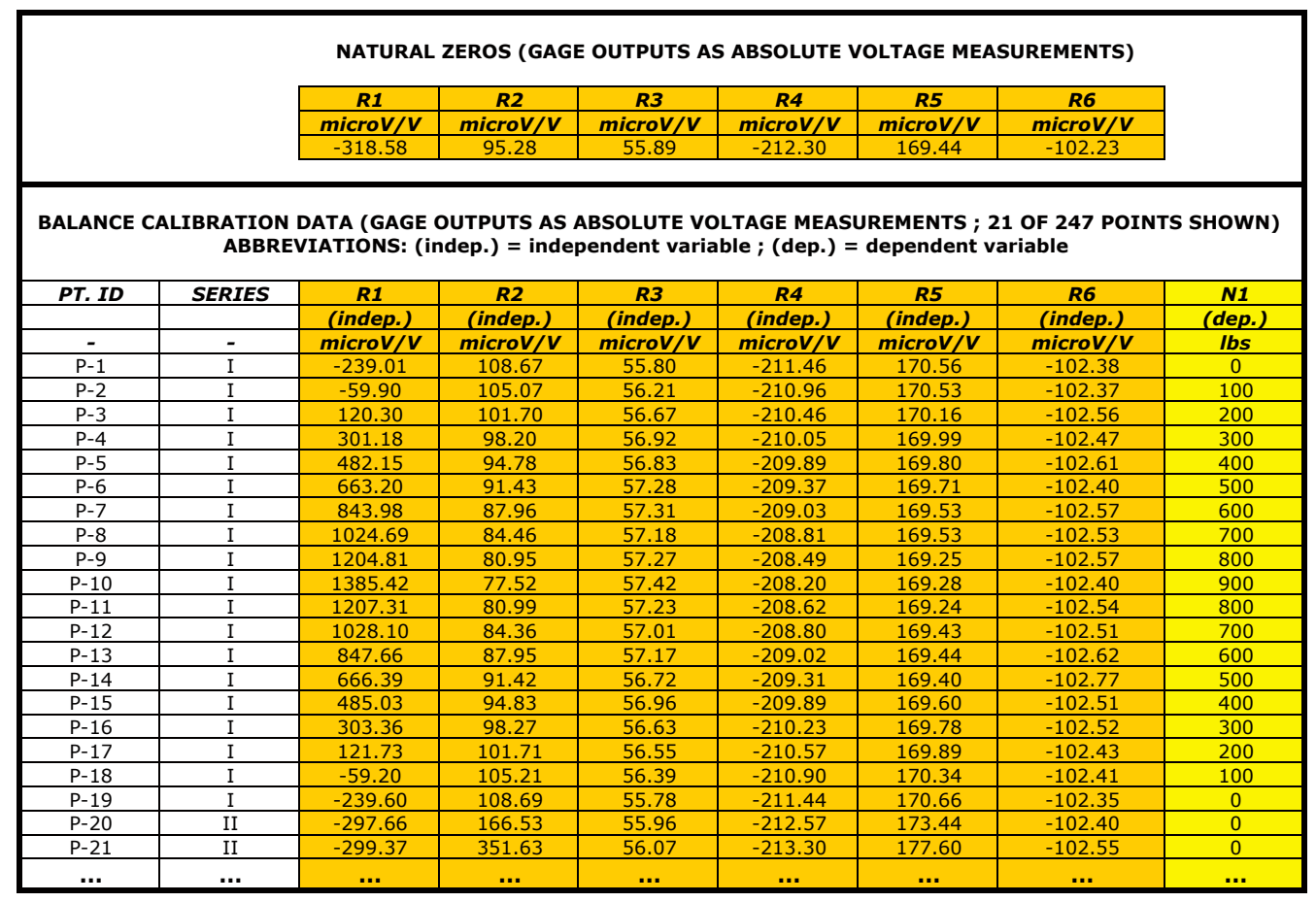

Fig. 4a Non-Iterative Analysis Technique: Balance calibration data using absolute voltage measurements.

\begin{tabular}{|c|c|c|c|c|c|c|c|c|}
\hline & & \multicolumn{6}{|c|}{ NATURAL ZEROS (GAGE OUTPUT DIFFERENCE RELATIVE TO NATURAL ZERO) } & \\
\hline & & $R 1$ & $R 2$ & R3 & R4 & R5 & $R 6$ & \\
\hline & & microv/V & microv/V & microV/V & microv/V & $\operatorname{microV} / V$ & microV/V & \\
\hline & & 0.00 & 0.00 & 0.00 & 0.00 & 0.00 & 0.00 & \\
\hline \multicolumn{9}{|c|}{$\begin{array}{l}\text { BALANCE CALIBRATION DATA (GAGE OUTPUT DIFFERENCE RELATIVE TO NATURAL ZERO ; } 21 \text { OF } 247 \text { POINTS SHOWN) } \\
\text { ABBREVIATIONS: (indep.) = independent variable ; (dep.) = dependent variable }\end{array}$} \\
\hline PT. ID & SERIES & $R 1$ & $R 2$ & $R 3$ & $R 4$ & $R 5$ & $R 6$ & N1 \\
\hline & & (indep.) & (indep.) & (indep.) & (indep.) & (indep.) & (indep.) & (dep.) \\
\hline- & - & microv/V & microv/V & microv/V & microv/V & microv/V & microv/V & lbs \\
\hline $\mathrm{P}-1$ & I & 79.57 & 13.40 & -0.09 & 0.84 & 1.12 & -0.15 & 0 \\
\hline $\mathrm{P}-2$ & I & 258.68 & 9.79 & 0.31 & 1.34 & 1.08 & -0.14 & 100 \\
\hline $\mathrm{P}-3$ & I & 438.88 & 6.42 & 0.78 & 1.84 & 0.71 & -0.33 & 200 \\
\hline $\mathrm{P}-4$ & I & 619.77 & 2.93 & 1.03 & 2.25 & 0.55 & -0.24 & 300 \\
\hline $\mathrm{P}-5$ & I & 800.73 & -0.50 & 0.93 & 2.41 & 0.36 & -0.38 & 400 \\
\hline $\mathrm{P}-6$ & I & 981.78 & -3.85 & 1.39 & 2.93 & 0.27 & -0.17 & 500 \\
\hline P-7 & I & 1162.56 & -7.31 & 1.42 & 3.27 & 0.09 & -0.34 & 600 \\
\hline $\mathrm{P}-8$ & I & 1343.27 & -10.81 & 1.28 & 3.49 & 0.09 & -0.30 & 700 \\
\hline $\mathrm{P}-9$ & I & 1523.39 & -14.33 & 1.38 & 3.81 & -0.19 & -0.34 & 800 \\
\hline $\mathrm{P}-10$ & I & 1704.01 & -17.76 & 1.52 & 4.10 & -0.16 & -0.17 & 900 \\
\hline $\mathrm{P}-11$ & I & 1525.89 & -14.29 & 1.34 & 3.68 & -0.20 & -0.31 & 800 \\
\hline $\mathrm{P}-12$ & I & 1346.68 & -10.91 & 1.12 & 3.50 & -0.01 & -0.28 & 700 \\
\hline $\mathrm{P}-13$ & I & 1166.24 & -7.33 & 1.28 & 3.28 & 0.00 & -0.39 & 600 \\
\hline P-14 & I & 984.97 & -3.85 & 0.83 & 2.99 & -0.04 & -0.54 & 500 \\
\hline $\mathrm{P}-15$ & I & 803.61 & -0.45 & 1.07 & 2.41 & 0.16 & -0.28 & 400 \\
\hline P-16 & I & 621.94 & 2.99 & 0.73 & 2.07 & 0.34 & -0.29 & 300 \\
\hline P-17 & I & 440.31 & 6.43 & 0.66 & 1.73 & 0.45 & -0.20 & 200 \\
\hline P-18 & I & 259.38 & 9.94 & 0.50 & 1.40 & 0.90 & -0.18 & 100 \\
\hline $\mathrm{P}-19$ & I & 78.98 & 13.42 & -0.11 & 0.86 & 1.21 & -0.12 & 0 \\
\hline $\mathrm{P}-20$ & II & 20.92 & 71.25 & 0.06 & -0.27 & 4.00 & -0.17 & 0 \\
\hline $\mathrm{P}-21$ & II & 19.21 & 256.35 & 0.18 & -1.00 & 8.16 & -0.32 & 0 \\
\hline$\ldots$ & $\ldots$ & $\ldots$ & $\ldots$ & $\ldots$ & $\ldots$ & $\ldots$ & $\ldots$ & $\ldots$ \\
\hline
\end{tabular}

Fig. $4 \mathrm{~b} \underline{\text { Non-Iterative Analysis Technique: Balance calibration data using gage output differences. }}$

American Institute of Aeronautics and Astronautics 


\begin{tabular}{|c|c|c|c|c|}
\hline $\begin{array}{c}\text { Case } \\
\text { No. }\end{array}$ & $\begin{array}{c}\text { Output } \\
\text { Type }\end{array}$ & $\begin{array}{c}\text { Intercept } \\
\text { used } ?\end{array}$ & $\begin{array}{c}\text { Tare Load } \\
\text { Iter. Method }\end{array}$ & $\begin{array}{c}N 1, N 2, S 1, \\
S 2, A F, R M\end{array}$ \\
\hline \hline 1 & raw & yes & Method A & converged \\
\hline 2 & raw & yes & Method B & converged $^{\dagger}$ \\
\hline 3 & raw & no & Method A & not allowed \\
\hline 4 & raw & no & Method B & not allowed $^{\dagger}$ \\
\hline 5 & diff. & yes & Method A & converged $^{\text {converged }}$ \\
\hline 6 & diff. & yes & Method B & converged $^{\text {con }}$ \\
\hline 7 & diff. & no & Method A & converged \\
\hline 8 & diff. & no & Method B & converged \\
\hline
\end{tabular}

raw $=$ absolute voltage measurement $;$ diff. = difference relative to natural zero

${ }^{\dagger}$ Not allowed because the direct use of absolute (raw) voltage measurements always requires an intercept term in the math model.

Fig. 5a Iterative Analysis Technique: Tare load iteration convergence behavior for the MK-III-C data set.

\begin{tabular}{|c|c|c|c|c|c|c|c|c|c|}
\hline $\begin{array}{l}\text { Case } \\
\text { No. }\end{array}$ & $\begin{array}{l}\text { Output } \\
\text { Type }\end{array}$ & $\begin{array}{c}\text { Intercept } \\
\text { used? }\end{array}$ & $\begin{array}{l}\text { Tare Load } \\
\text { Iter. Meth. }\end{array}$ & $N 1$ & $N 2$ & $S 1$ & $S 2$ & $A F$ & $R M$ \\
\hline 9 & raw & yes & Method A & div. & div. & div. & div. & div. & div. \\
\hline 10 & raw & yes & Method B & conv. & conv. & conv. & conv. & conv. & conv. \\
\hline 11 & raw & no & Method A & n. a. ${ }^{\dagger}$ & n. a. ${ }^{\dagger}$ & n. a. ${ }^{\dagger}$ & n. a. ${ }^{\dagger}$ & n. a. ${ }^{\dagger}$ & n. a. ${ }^{\dagger}$ \\
\hline 12 & raw & no & Method B & n. a. ${ }^{\dagger}$ & n. a. ${ }^{\dagger}$ & n. a. ${ }^{\dagger}$ & n. a. ${ }^{\dagger}$ & n. a. $^{\dagger}$ & n. a. ${ }^{\dagger}$ \\
\hline 13 & diff. & yes & Method A & div. & div. & div. & div. & div. & div. \\
\hline 14 & diff. & yes & Method B & conv. & conv. & conv. & conv. & conv. & conv. \\
\hline 15 & diff. & no & Method A & conv. & conv. & conv. & conv. & conv. & conv. \\
\hline 16 & diff. & no & Method B & conv. & conv. & conv. & conv. & conv. & conv. \\
\hline
\end{tabular}

raw $=$ absolute voltage measurement $;$ diff. $=$ difference relative to natural zero

conv. $=$ converged $;$ div. $=$ diverged or did not converge $;$ n. a. = not allowed

${ }^{\dagger}$ Not allowed because the direct use of absolute (raw) voltage measurements always requires an intercept term in the math model.

Fig. 5b Non-Iterative Analysis Technique: Tare load iteration convergence behavior for the MK-III-C data set. 


\begin{tabular}{|c|c|c|c|c|c|c|c|c|}
\hline $\begin{array}{l}\text { Load } \\
\text { Series }\end{array}$ & $\begin{array}{c}\text { Case } 1 \\
\text { (Meth. A) } \\
\text { [lbs] }\end{array}$ & $\begin{array}{c}\text { Case } 2 \\
\text { (Meth. B) } \\
\text { [lbs] }\end{array}$ & $\begin{array}{c}\text { Case } 3^{\dagger} \\
\text { (Meth. A) } \\
\text { [lbs] }\end{array}$ & $\begin{array}{c}\text { Case } 4^{\dagger} \\
\text { (Meth. B) } \\
\text { [lbs] }\end{array}$ & $\begin{array}{c}\text { Case } 5 \\
\text { (Meth. A) } \\
\text { [lbs] }\end{array}$ & $\begin{array}{c}\text { Case } 6 \\
\text { (Meth. B) } \\
\text { [lbs] }\end{array}$ & $\begin{array}{c}\text { Case } 7 \\
\text { (Meth. A) } \\
\text { [lbs] }\end{array}$ & $\begin{array}{c}\text { Case } 8 \\
\text { (Meth. B) } \\
\text { [lbs] }\end{array}$ \\
\hline II & 12.027 & 12.027 & - & - & 12.027 & 12.027 & 12.026 & 12.026 \\
\hline III & 15.220 & 15.220 & - & - & 15.220 & 15.220 & 15.220 & 15.220 \\
\hline V & -10.113 & -10.113 & - & - & -10.113 & -10.113 & -10.113 & -10.113 \\
\hline VI & 0.142 & 0.142 & - & - & 0.142 & 0.142 & 0.141 & 0.141 \\
\hline VII & 0.098 & 0.098 & - & - & 0.098 & 0.098 & 0.097 & 0.097 \\
\hline VIII & 0.001 & -0.001 & - & - & 0.001 & 0.001 & 0.000 & 0.000 \\
\hline IX & 0.170 & 0.170 & - & - & 0.170 & 0.170 & 0.169 & 0.169 \\
\hline XIII & 75.835 & 75.835 & - & - & 75.835 & 75.835 & 75.833 & 75.833 \\
\hline
\end{tabular}

${ }^{\dagger}$ No solution exists because required intercept term was omitted in math model.

Fig. 6a Case 1 to 8: Comparison of predicted tare loads for the load component $N 1$ in engineering units.

\begin{tabular}{|c|c|c|c|c|c|c|c|c|}
\hline $\begin{array}{l}\text { Load } \\
\text { Series }\end{array}$ & $\begin{array}{c}\text { Case } 9 \\
\text { (Meth. A) } \\
\text { [lbs] }\end{array}$ & $\begin{array}{c}\text { Case } 10 \\
\text { (Meth. B) } \\
\text { [lbs] }\end{array}$ & $\begin{array}{c}\text { Case } 11^{\dagger} \\
\text { (Meth. A) } \\
\text { [lbs] }\end{array}$ & $\begin{array}{c}\text { Case } 12^{\dagger} \\
\text { (Meth. B) } \\
\text { [lbs] }\end{array}$ & $\begin{array}{c}\text { Case } 13 \\
\text { (Meth. A) } \\
\text { [lbs] }\end{array}$ & $\begin{array}{c}\text { Case } 14 \\
\text { (Meth. B) } \\
\text { [lbs] }\end{array}$ & $\begin{array}{c}\text { Case } 15 \\
\text { (Meth. A) } \\
\text { [lbs] }\end{array}$ & $\begin{array}{c}\text { Case } 16 \\
\text { (Meth. B) } \\
\text { [lbs] }\end{array}$ \\
\hline II & diverged & 12.029 & - & - & diverged & 12.029 & 12.028 & 12.028 \\
\hline III & diverged & 15.221 & - & - & diverged & 15.221 & 15.221 & 15.221 \\
\hline $\mathrm{V}$ & diverged & -10.115 & - & - & diverged & -10.115 & -10.115 & -10.115 \\
\hline VI & diverged & 0.141 & - & - & diverged & 0.141 & 0.140 & 0.140 \\
\hline VII & diverged & 0.097 & - & - & diverged & 0.097 & 0.096 & 0.096 \\
\hline VIII & diverged & 0.002 & - & - & diverged & 0.002 & 0.001 & 0.001 \\
\hline IX & diverged & 0.170 & - & - & diverged & 0.170 & 0.169 & 0.169 \\
\hline XIII & diverged & 75.840 & - & - & diverged & 75.840 & 75.838 & 75.838 \\
\hline
\end{tabular}

${ }^{\dagger}$ No solution exists because required intercept term was omitted in math model.

Fig. 6 b Case 9 to 16: Comparison of predicted tare loads for the load component $N 1$ in engineering units. 


\begin{tabular}{|c|c|c|c|c|c|c|c|c|}
\hline $\begin{array}{l}\text { Load } \\
\text { Series }\end{array}$ & $\begin{array}{c}\text { Case } 1 \\
\text { (Meth. A) } \\
{[\%]}\end{array}$ & $\begin{array}{c}\text { Case } 2 \\
\text { (Meth. B) } \\
{[\%]}\end{array}$ & $\begin{array}{c}\text { Case } 3^{\dagger} \\
\text { (Meth. A) } \\
{[\%]}\end{array}$ & $\begin{array}{c}\text { Case } 4^{\dagger} \\
\text { (Meth. B) } \\
{[\%]}\end{array}$ & $\begin{array}{c}\text { Case } 5 \\
\text { (Meth. A) } \\
{[\%]}\end{array}$ & $\begin{array}{c}\text { Case } 6 \\
\text { (Meth. B) } \\
{[\%]}\end{array}$ & $\begin{array}{c}\text { Case } 7 \\
\text { (Meth. A) } \\
{[\%]}\end{array}$ & $\begin{array}{c}\text { Case } 8 \\
\text { (Meth. B) } \\
{[\%]}\end{array}$ \\
\hline II & 1.34 & 1.34 & - & - & 1.34 & 1.34 & 1.34 & 1.34 \\
\hline III & 1.69 & 1.69 & - & - & 1.69 & 1.69 & 1.69 & 1.69 \\
\hline $\mathrm{V}$ & -1.12 & -1.12 & - & - & -1.12 & -1.12 & -1.12 & -1.12 \\
\hline VI & 0.02 & 0.02 & - & - & 0.02 & 0.02 & 0.02 & 0.02 \\
\hline VII & 0.01 & 0.01 & - & - & 0.01 & 0.01 & 0.01 & 0.01 \\
\hline VIII & 0.00 & 0.00 & - & - & 0.00 & 0.00 & 0.00 & 0.00 \\
\hline IX & 0.02 & 0.02 & - & - & 0.02 & 0.02 & 0.02 & 0.02 \\
\hline XII & -8.52 & -8.52 & - & - & -8.52 & -8.52 & -8.52 & -8.52 \\
\hline XIII & 8.43 & 8.43 & - & - & 8.43 & 8.43 & 8.43 & 8.43 \\
\hline
\end{tabular}

${ }^{\dagger}$ No solution exists because required intercept term was omitted in math model.

Fig. 7a Case 1 to 8: Comparison of predicted tare loads for the load component $N 1$ in percent of load capacity.

\begin{tabular}{|c|c|c|c|c|c|c|c|c|}
\hline $\begin{array}{l}\text { Load } \\
\text { Series }\end{array}$ & $\begin{array}{c}\text { Case } 9 \\
\text { (Meth. A) } \\
{[\%]}\end{array}$ & $\begin{array}{c}\text { Case } 10 \\
\text { (Meth. B) } \\
{[\%]}\end{array}$ & $\begin{array}{c}\text { Case } 11^{\dagger} \\
(\text { Meth. A) } \\
{[\%]}\end{array}$ & $\begin{array}{c}\text { Case } 12^{\dagger} \\
\text { (Meth. B) } \\
{[\%]}\end{array}$ & $\begin{array}{c}\text { Case } 13 \\
\text { (Meth. A) } \\
{[\%]}\end{array}$ & $\begin{array}{c}\text { Case } 14 \\
\text { (Meth. B) } \\
{[\%]}\end{array}$ & $\begin{array}{c}\text { Case } 15 \\
\text { (Meth. A) } \\
{[\%]}\end{array}$ & $\begin{array}{c}\text { Case } 16 \\
\text { (Meth. B) } \\
{[\%]}\end{array}$ \\
\hline II & diverged & 1.34 & - & - & diverged & 1.34 & 1.34 & 1.34 \\
\hline III & diverged & 1.69 & - & - & diverged & 1.69 & 1.69 & 1.69 \\
\hline V & diverged & -1.12 & - & - & diverged & -1.12 & -1.12 & -1.12 \\
\hline VI & diverged & 0.02 & - & - & diverged & 0.02 & 0.02 & 0.02 \\
\hline VII & diverged & 0.01 & - & - & diverged & 0.01 & 0.01 & 0.01 \\
\hline VIII & diverged & 0.00 & - & - & diverged & 0.00 & 0.00 & 0.00 \\
\hline IX & diverged & 0.02 & - & - & diverged & 0.02 & 0.02 & 0.02 \\
\hline XIII & diverged & 8.43 & - & - & diverged & 8.43 & 8.43 & 8.43 \\
\hline
\end{tabular}

${ }^{\dagger}$ No solution exists because required intercept term was omitted in math model.

Fig. $7 \mathbf{b}$ Case 9 to 16: Comparison of predicted tare loads for the load component $N 1$ in percent of load capacity. 